\title{
Subsurface aeration of tidal wetland soils: root-system structure and aerenchyma connectivity in Spartina (Poaceae)
}

\author{
Dirk Granse $^{1,{ }^{*}}$, Jürgen Titschack ${ }^{2,3}$, Malika Ainouche ${ }^{4}$, Kai Jensen ${ }^{1}$, and Ketil Koop-Jakobsen ${ }^{2,5}$ \\ ${ }^{1}$ Applied Plant Ecology, Institute of Plant Science and Microbiology, Universität Hamburg, Germany \\ ${ }^{2}$ MARUM - Center for Marine Environmental Sciences, University of Bremen, Germany \\ ${ }^{3}$ Senckenberg am Meer, Marine Research Department, 26382 Wilhelmshaven, Germany \\ ${ }^{4}$ University of Rennes 1, UMR CNRS 6553 Ecobio, Bât. 14A, Campus Scientifique de Beaulieu, \\ 35042, Rennes Cedex, France \\ ${ }^{5}$ Alfred Wegener Institute - Wadden Sea Station, Sylt, Germany \\ *Corresponding author, e-mail: dirk.granse@uni-hamburg.de
}

\section{August 10, 2021}

Manuscript type: Full paper

Abstract Root-aerenchyma in wetland plants facilitate transport of oxygen from aboveground sources (atmosphere and photosynthesis) to belowground roots and rhizomes, where oxygen can leak out and oxygenate the otherwise anoxic soils. In salt marshes, the soil oxygenation capacity varies among different Spartina-taxa, but little is known about structural pattern and connectivity of root-aerenchyma that facilitates this gas transport. Both environmental conditions and ploidy level play a role for the root-system morphology. Root-system morphology of polyploid Spartina-taxa was studied, quantifying root-tissue volume and rootaerenchyma volume of hexaploid Spartina alterniflora, Spartina maritima, and Spartina $\times$ townsendii as well as dodecaploid Spartina anglica from different habitats. Computed tomography (CT)-scan image analysis was applied to quantify the volume of roots and aerenchyma, and to determine the root-system structure (ratio of aerenchyma to roottissue volumes) and aerenchyma connectivity. On average, Spartina-roots accounted for $12 \%$ $(\mathrm{v} / \mathrm{v})$ and root-aerenchyma accounted for $1 \%(\mathrm{v} / \mathrm{v})$ of the soil volume in the pioneer marsh. About $90 \%$ (v/v) of all roots were associated with aerenchyma. Root-system structures of 
S. $\times$ townsendii and S. anglica differed and showed clear responses to habitat conditions, such as flooding regime and redox potential. The development of large well-connected aerenchyma fragments were specifically shown in S. anglica and to a minor extend in S. maritima. Aerenchyma in S. alterniflora and $S . \times$ townsendii consisted only of smaller fragments. Spartina-dominated tidal pioneer marsh soils show high connectivity with the atmosphere via root-aerenchyma. The high ploidy level in S. anglica comes along with high connectivity in root-aerenchyma.

Keywords: marker-controlled watershed segmentation $\cdot$ skeleton analysis $\cdot$ tidal salt marsh ecosystem $\cdot$ Sporobolus $\cdot$ polyploidization $\cdot$ whole genome duplication

\section{Introduction}

Spartina-populations cover substantial areas in tidal wetlands around the globe (e.g., An et al., 2007; Esselink et al., 2009; Strong and Ayres, 2013; Bortolus et al., 2015). Spartina-plants are known for their capacity to engineer coastal habitats (Hulzen et al., 2007; Balke et al., 2012), catching and fixing tidal sediments (e.g., König, 1948; Ranwell, 1967), oxygenating the soil via plant-mediated oxygen transport (Teal and Kanwisher, 1966; Maricle and Lee, 2007; Koop-Jakobsen et al., 2017), and thereby facilitating nitrogen retention (Hamersley and Howes, 2005; Koop-Jakobsen and Giblin, 2010; De Lange and Paulissen, 2016). The belowground biomass structure and oxygen transport capacity of perennial Spartina grasses play a key role for these ecosystem functions in salt marshes and for connecting tidal soils with the atmosphere.

Spartina thrives in low-laying salt marshes (pioneer zone) and withstand waterlogged anoxic and sulfidic soil conditions as well as daily flooding by sea water (Gray et al., 1991). In this stressful environment, belowground oxygen transport plays a key-role providing 
oxygen for root respiration. Furthermore, roots can leak oxygen to the rhizosphere, mainly near the root-tips (Armstrong, 1972; Visser et al., 2000; Koop-Jakobsen and Wenzhöfer, 2015), where oxygen improves nutrient uptake (Bradley and Morris, 1990; Lai et al., 2012) and acts as an oxidant that decreases the impact of toxic, reduced inorganic compounds, especially $\mathrm{H}_{2} \mathrm{~S}$, by oxidizing them (Lee et al., 1999; Pezeshki, 2001; Lee, 2003).

To facilitate oxygen transport to root-cells in waterlogged soils, many wetland plants exploit air-filled spaces inside roots, commonly termed aerenchyma (Justin and Armstrong, 1987; Jackson and Armstrong, 1999; Evans, 2004). The translocated oxygen originates directly from the atmosphere and from photosynthesis (Koop-Jakobsen and Wenzhöfer, 2015; Koop-Jakobsen et al., 2018), and can be passed through the stem via channels of low gas-flow resistance into the root-aerenchyma, by pressurized continuous gas-flow driven by venturiand humidity-induced convection (Armstrong et al., 1992; Brix et al., 1992; Armstrong and Armstrong, 2009).

Root-aerenchyma formation can alter the biomechanical characteristics of roots (Justin and Armstrong, 1987). Justin and Armstrong (1987) demonstrated that wetland species show predominantly cubic cell packing in the cortex of roots as a prerequisite for effective lysigenous aerenchyma formation by apoptotic cell death under waterlogged conditions. Opposed to cubic packing, hexagonal packing of cells in the root cortex provides a higher resistance against biomechanical stress (Justin and Armstrong, 1987). As a response to mechanical stress imposed by the conditions in salt marsh habitats, a significant proportion of hexagonal packing was observed in Spartina anglica (Justin and Armstrong, 1987). At the same time, Spartina-taxa exhibit a high capacity to form aerenchyma in response to waterlogged conditions (Maricle and Lee, 2007). This leads to the assumption of a trade-off between the suitable root-oxygenation by forming aerenchyma and the maintenance of biomechanical integrity of roots by avoiding aerenchyma. 
The biomechanical integrity of roots (high tensile strength) is regarded as a prerequisite for anchoring in unstable soils of salt marsh and periglacial environments (Van Eerdt, 1985; Hudek et al., 2017a). In salt marshes, plants have to cope with varying habitat conditions of both a high demand of roots for oxygen imposed by waterlogged conditions and tides (e.g., Koop-Jakobsen and Gutbrod, 2019; Mueller et al., 2020) as well as physicomechanical stress imposed by hydrodynamic forces (tidal currents and waves; e.g., French and Stoddart, 1992; Widdows et al., 2008; Callaghan et al., 2010; Edmaier et al., 2011; Belliard et al., 2019). Therefore, the root-system structure, i.e., the spatial distribution of root-tissue and rootaerenchyma in the three-dimensional (3D) root-system, is an important factor for the establishment and survival of Spartina plants in salt marsh habitats.

Different phenotypes driven by variation of soil chemistry are well-known for the aboveground biomass (Valiela et al., 1978; Mendelssohn et al., 1981; Mendelssohn and McKee, 1988) and the belowground biomass (Thompson et al., 1991; Redelstein et al., 2018) in Spartina. Four polyploid Spartina-taxa are common on European saltmarshes (Marchant, 1967, 1968): The native hexaploid Spartina maritima (Curtis) Fernald $(2 n=6 x=60)$, the introduced (native American) hexaploid Spartina alterniflora Loiseleur $(2 n=6 x=62)$, their homoploid $\mathrm{F}_{1}$-hybrid Spartina $\times$ townsendii $\mathrm{H}$. Groves \& J. Groves $(2 \mathrm{n}=6 \mathrm{x}=62)$, and their derived allododecaploid Spartina anglica C.E. Hubbard $(2 \mathrm{n}=12 \mathrm{x}=120-124)$, which has rapidly expanded in range since its formation during the $19^{\text {th }}$ century (Ainouche et al., 2009). The hybrids $S . \times$ townsendii and $S$. anglica inhabit a wide variety of habitats and marsh zones (e.g., Gray et al., 1991; Hacker et al., 2001; Granse et al., 2020) in- and outside the parental range (e.g., Maricle et al., 2006; Wong et al., 2018; Proença et al., 2019, Granse et al., accepted). S. anglica and parental S. alterniflora have gained attention as invasive species which spread in coastal habitats around the globe (e.g., Ranwell, 1967; An et al., 2007; Strong and Ayres, 2013; Bortolus et al., 2015; Shang et al., 2019). The high affinity of both 
S. anglica and S. alterniflora for belowground relocated oxygen is considered to be beneficial in hypoxic soils and may increase their invasive success (Maricle et al., 2006; Maricle and Lee, 2007).

Polyploidy has been shown as an important mechanism shaping Spartina-genome evolution (Ainouche et al., 2012) as well as phenotypic evolution, including stress tolerance and plasticity in these species (Cavé-Radet et al., 2018). Another immediate consequence of polyploidization is described as the so-called "gigas effect", indicating marked increases in cell size that can result in general in larger structures, like e.g., larger flowers, pollen grains, and seeds (Müntzing, 1936; Stebbins, 1971; Ramsey and Schemske, 2002; Meeus et al., 2020). Studies have also demonstrated that polyploidization can cause allometric effects due to larger cell and tissue volumes (Finigan et al., 2012; Doyle and Coate, 2019; Roddy et al., 2019; Fox et al., 2020), which has been shown to alter the vascular transport network resulting in higher hydraulic conductivity of the xylem (Maherali et al., 2009). Therefore, Spartina-taxa with different ploidy levels (hexa- and dodecaploid) may show a marked variation in root-system structure and aerenchyma.

Oxygen transport from the atmosphere to the root tips requires that aerenchyma provide an unbroken airspace-compartment from the stems to the roots (Teal and Kanwisher, 1966). By comparing aerenchyma development responses to flooding (Maricle and Lee, 2002) and gas-flow capacities (Lee, 2003), dodecaploid S. anglica was shown to transport oxygen more efficiently to root cells than hexaploid Spartina alterniflora, which may be based on ploidy level effects.

Medicinal computed tomography image analysis facilitates studying the 3D root morphology of vegetation in undisturbed tidal marsh soils (Davey et al., 2011; Blum and Davey, 2013; Hanson et al., 2016; Wigand et al., 2016). CT-scanning enables the distinction 
of air-spaces, organic structures and mineral particulates by means of a standardized X-ray response (Hounsfield units HU; Hounsfield, 1979), which allows the 3D root-system structures (root-tissue and root-aerenchyma) to be reconstructed in-silico using segmentation and skeleton analysis methods (Gao et al., 2019; Chirol et al., 2021).

In this study, CT-scanning was applied to investigate the root-systems of four Spartinataxa (Fig. 1), which represent a particularly suitable model system to explore the consequences of recent hybridization and polyploidy (Ainouche et al., 2012). The study aims to elucidate the difference among taxa naturally occurring along the Atlantic coastline of Northern Europe: the $\mathrm{F}_{1}$-hybrid $S . \times$ townsendii and the neododecaploid $S$. anglica in the following termed Spartina-hybrids, as well as the maternal parent S. alterniflora and paternal parent Spartina maritima, in the following termed (hexaploid) Spartina-parents or parental taxa. Spartina-hybrids grow in close vicinity to each other at sites in the eastern part of the European Wadden Sea (Granse et al., accepted), while parental taxa can be found at the Atlantic coast in France (Fig. 2A). The differences in root-system structures can be identified by the proportion of roots associated with aerenchyma and the ratio of aerenchyma to roottissue. Thereby, roots with discontinuous aerenchyma will have structural functions, such as maintaining the biomechanical integrity of roots, but show resistance to gas-flow. Therefore, in addition, aerenchyma connectivity is estimated from continuous aerenchyma as a proxy for the capacity of unimpeded gas-exchange between the atmosphere and root-cells.

In order to elucidate the impact of habitat conditions and polyploidization, we hypothesize that

- Spartina shows distinct root-system structures in response to habitat conditions differing in flooding regime, soil characteristics, and tidal hydrodynamics, and 
- Spartina-taxa of different ploidy levels (hexa- and dodecaploid) show distinct rootsystem structures when growing in similar habitat conditions, and

- the allododecaploid S. anglica shows a higher aerenchyma connectivity than the hexaploid $\mathrm{F}_{1}$-hybrid and its parental Spartina-taxa.

\section{Methods}

\subsection{Study design}

Figure1.pdf; See also affiliated PDF-file version!

Fig. 1: Illustration of kinship relations between Spartina-taxa with respect to ploidy levels (hexaploid, dodecaploid), $\mathrm{F}_{1}$-hybrid formation and whole genome duplication (polyploidization), adapted from Ainouche et al. (2012).

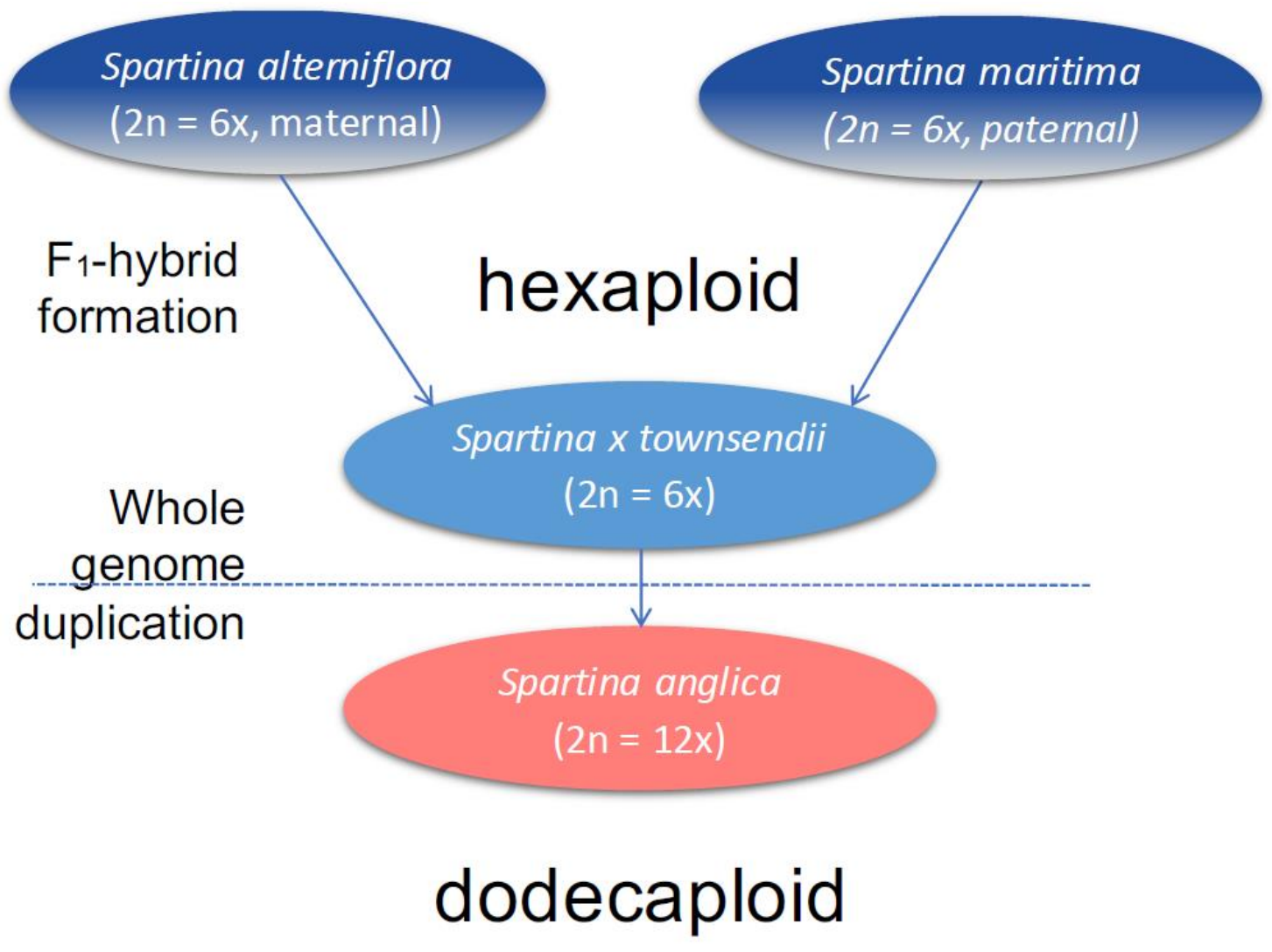


Figure2.png; See also affiliated PDF-file version!

Fig. 2: A) Sampling sites of Spartina soil cores at the Atlantic coast in Brittany, France (S. alterniflora, S. maritima), and in the European Wadden Sea $(S . \times$ townsendii, S. anglica) at Sönke-Nissen-Koog (SNK), Schleswig-Holstein, Germany. B) Positions of sampled Spartina at SNK in different habitats. C) Scheme of sampling positions of $S . \times$ townsendii (habitats: tidal flat and pioneer marsh) and $S$. anglica (habitats: pioneer marsh and tidal creek) at the SNK study site with respect to the elevation of sampling positions to mean high tide (MHT; see also environmental parameters in Table 1). 


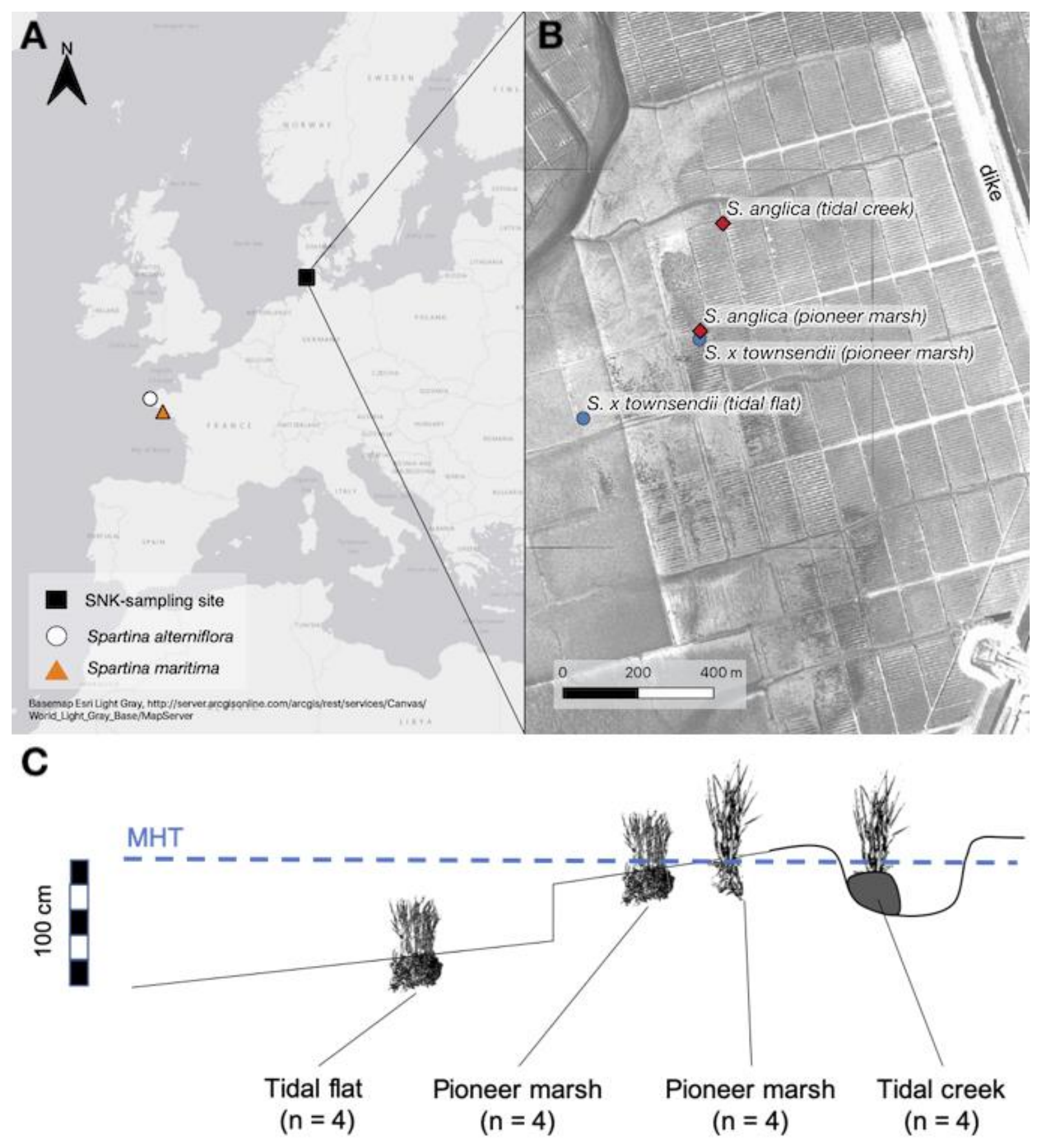

Spartina $x$ townsendii

Spartina anglica

The parental Spartina-taxa of the hybrids were sampled at the Atlantic coast in Brittany,

France (S. maritima: Plouharnel, 47॰35'N 3。07'W; S. alterniflora: Faou estuary,

48。17’46"N 4。11'00"W; Fig. 2A). 
In order to investigate the impact of environmental conditions on the development of the belowground biomass, hexaploid $S . \times$ townsendii and dodecaploid $S$. anglica were collected at Sönke-Nissen-Koog, Schleswig-Holstein, Germany (SNK; 54॰36’N 8。53’E; Fig. 2B), considering differences in elevation, bulk density, soil redox potential, and microhabitat (tidal flat, pioneer marsh, tidal creek; see Fig. 2C, Table 1). Flooding and exposure to hydrodynamic forces are more frequent and inundations last longer at lower elevations. The Spartina-clone at the tidal flat position showed the lowest elevation and the flooding duration was longer compared to the other clones. The Spartina-clone in the tidal creek have been growing on a hummock, which was exposed to tidal currents.

The ploidy levels of Spartina-taxa were determined according to Granse et al. (accepted) by means of flow-cytometer analysis (Partec GmbH, Münster, Germany) using a DAPI staining protocol and a standard (Pisum sativum). The combination of ploidy level and habitat resulted in four sampling positions, in the following denoted as Spartina-clones termed Spartina $\times$ townsendii (tidal flat), Spartina $\times$ townsendii (pioneer marsh), Spartina anglica (pioneer marsh), and Spartina anglica (tidal creek). These sampling positions allowed to test the root-system responses of the hybrids to different flooding regimes with four replicates $(n$ =4) at each position. In particular, this study design allowed for comparisons among individual Spartina-taxa growing in different habitats, and among different Spartina-taxa growing in identical habitats.

\subsection{Soil Characteristics and stem density}

At the Wadden Sea site, soil parameters (elevation, redox potential) were measured in the habitats with $S . \times$ townsendii and S. anglica (see Fig. 2C) in August 2017 before sampling soil cores for CT-scanning. 
Elevation mean high tide (MHT) was referenced against the German Ordnance Datum and regional mean high tide gauge as described in Granse et al. (2020).

Soil bulk density was determined in the topmost layer $(0-5 \mathrm{~cm})$ using a volumetric ring $\left(100 \mathrm{~cm}^{3}\right)$. Litter layers were removed prior to sampling. Soil dry weight was determined after air drying the volumetric cores at $105 \circ \mathrm{C}$ for $48 \mathrm{~h}$.

The redox potential was measured before and after a tidal inundation at high tide. Redox values were examined at $5 \mathrm{~cm}$ soil depth $(n=3)$ using a platinum-tipped electrode and an $\mathrm{Ag} / \mathrm{AgCl}$ reference electrode after Mansfeldt (2003).

The reducing depth was determined by visual identification as the depth where iron sulphide precipitation is clearly visible, as an easily distinguishable black layer. In the presence of sulphur, iron is reduced forming black colored Pyrite, which is widely independent of tidal and seasonal fluctuations and therefore a useful proxy for identification of permanently anaerobic soil horizons.

Table 1: Soil characteristics and stem densities of $S . \times$ townsendii and S. anglica $(n=1)$. Table1.docx; For table details also see affiliated PDF-file version!

\subsection{Soil core sampling for CT-scanning analysis}

The soil cores of Spartina-hybrids were sampled in March 2018 at the SNK field site in the Wadden Sea, Schleswig-Holstein, Germany (Fig. 2). The soil cores of the parental taxa of the Spartina-hybrids were collected in June 2018 at the Atlantic coast in Brittany, France. At each of the sampling positions, four Spartina soil cores were sampled $(n=4)$ and the GPS 
coordinates recorded. All sampled Spartina-habitats represent individual Spartina-clones, which were monospecific and clearly demarcated against other Spartina-clones.

All soil cores were sampled using a metal-corer with a diameter of $25 \mathrm{~cm}$ and $30 \mathrm{~cm}$ in height. After sampling, the soil cores were potted in plastic pots $(\mathrm{d}=29 \mathrm{~cm}, \mathrm{~h}=23 \mathrm{~cm}$; material: polypropylene). Gaps were filled with autoclaved sand. Until CT-scanning in September 2018, the samples were kept in a tidal outdoor-basin at Universität Hamburg to acclimate the plants by simulating two inundations per day with artificial sea water ( $20 \mathrm{psu})$. A salinity level approximately $66 \%$ the full-strength of seawater was shown to prevent roothair growth (Bouma et al., 2000). Before CT-scanning, the pots were placed into cylindrical polypropylene transport-container (density $0.9 \mathrm{~g} \mathrm{~cm}^{-3}$; wall thickness of pot and transport container $<1 \mathrm{~mm}$ ). The low wall thickness, the low density and the light elemental composition (mainly carbon and hydrogen) of the pots and transport containers secured a minimal x-ray attenuation. The preparation of the pots for their transport were conducted 24 hours before CT-scanning. Therefore, the pots were in drained state during CT-scanning.

\subsection{Computed tomography and CT-scan image analysis}

Computed tomography scanning and CT-scan image analysis are described in detail in the Supplementary Material (CT-scan image analysis methods) and are only briefly summarized here.

\subsubsection{Computed tomography}

All Spartina-cores were scanned by a Toshiba Aquilion 64 computer tomograph at the hospital Klinikum Bremen-Mitte, Bremen, Germany, with an X-ray source voltage of $120 \mathrm{kV}$ and a current of $600 \mathrm{~mA}$. The resulting CT-image stacks contain grey-scale images of X-ray attenuation in standardized Hounsfield Units (HU; air: -1000 HU, distilled water: 0 HU; Hounsfield, 1979). Medicinal CT-scanners are regularly calibrated with a standardized 
procedure using phantoms containing various materials with different densities. Using HU provides principal compatibility of data from different medical-CT devices (Cnudde and Boone, 2013). The resolution of medicinal CT-scanning is limited to approximately $0.4 \mathrm{~mm}$ (reconstruction unit), meaning that roots with a diameter of $1 \mathrm{~mm}$ are represented by 3 voxel.

\subsubsection{CT-scan image analysis}

The CT-scans of the cores were cropped to cylindrical shape $(\mathrm{d}=18 \mathrm{~cm}, \mathrm{~h}=25 \mathrm{~cm})$ representing the top $20 \mathrm{~cm}$ of the soil and $5 \mathrm{~cm}$ of the aboveground biomass.

To differentiate between roots (including aerenchyma), sediment, and air-filled pore space we followed a specific segmentation strategy. First, roots including the aerenchyma and sediment were segmented using a marker-controlled watershed algorithm. This algorithm does not require calibration of $\mathrm{HU}$ as necessary for threshold-based segmentation methods because X-ray attenuation is influenced by the density and the composition of the material. In contrast to a threshold-based segmentation method, used for example by Davey et al. (2011), the marker-controlled watershed algorithm allows to compensate X-ray attenuation differences within and between samples as markers are set in areas that can be designated without difficulty to one or another material. The algorithm searches the boundary between the materials by expanding the areas of the markers to the region of maximal change in X-ray attenuation. Second, the values within the segmented areas were averaged with a moving window of $15 \times 15$ voxels. As air filled pores and bioturbation traces are exclusively filled by air, they exhibited clearly lower values than roots with or without aerenchyma. To separate the latter, we used a threshold segmentation with a value of $-250 \mathrm{HU}$. Third, within the remaining root material, we separated root-tissue and root-aerenchyma by threshold segmentation with a threshold of $-500 \mathrm{HU}$. The separation of aerenchyma from root-tissue is not affected by material-density or material-composition and could be separated with a 
threshold segmentation without calibration because the materials between the samples are always the same, root-tissue versus air. Furthermore, we checked that the aerenchyma is always connected to a root-tissue.

The root-system structure was identified by means of skeleton analysis (automated detection of the central root axes). Afterwards the root-system characteristics (root-tissue and root-aerenchyma volumes) were quantified by means of a voxel-based reconstruction of the root-system from the root-skeleton. The root-tissue and root-aerenchyma volumes are reported as mean per soil depth profile. The percentage of "roots with aerenchyma" were calculated by dividing the volume of roots which contain aerenchyma by the total root volume (root-tissue + root-aerenchyma).

\subsubsection{X-ray density}

As approximation for the material densities inside the soil core body (excluding: roots, aerenchyma, air-spaces) the mean X-ray attenuation in HU per soil depth profile were calculated. A two-category density classification (sediment fraction) was used according to Davey et al. (2011), separating X-ray densities into particulates (< $750 \mathrm{HU}$; clay, silt, precipitates, and peat) and sand ( $\geq 750 \mathrm{HU})$.

\subsubsection{Aerenchyma connectivity}

The aim of the aerenchyma connectivity analysis was to identify pathways of low resistance that facilitate gas-flow from the top soil into deep soils. Unimpeded transport of gaseous molecules over longer distances is necessary for belowground gas transport and requires aerenchyma, which are well connected from the surface to the roots. If the air-filled aerenchyma compartments are fragmented, unimpeded gas flow is not possible. Furthermore, it is a requirement that the aerenchyma has a considerable length and width. Short and thick rhizomes may have a considerable volume, but do not facilitate long-distance transport. 
In order to investigate the morphological differences among the Spartina-clones controlling their gas transport capacity, we conducted an analysis of aerenchyma fragment volumes, as a proxy for aerenchyma connectivity. The analysis was based on the root-skeleton reconstruction, and specifically targeted rhizomes facilitating long-distance transport, which had a diameter $\geq 1.4 \mathrm{~mm}$ and a length $\geq 70 \mathrm{~mm}$. Spartina-clones with the largest aerenchyma fragment volumes were considered to have highest aerenchyma connectivity. Each individual aerenchyma fragment was assigned to a unique color in the reconstruction images. This allows for visual distinction of aerenchyma consisting of fewer large fragments, which are all connected, and aerenchyma consisting of many smaller fragments, which are not connected. The term "extraordinarily extended" is in the following used to target aerenchyma fragments with a volume orders of magnitude larger than the median volume (identified as outlier outside the 1.5 of the interquartile range). Aerenchyma fragments which expanded over more than one rhizome will be termed "connected aerenchyma network".

\subsection{Software and statistics}

Geographic maps were created using QGIS 3 (Madeira) with a HCMGIS-plugin (including Esri World Light Grey Basemap). The CT-scan images were processed with the ZIB edition of the Amira software (version 2019.35, Stalling et al., 2005, http://amira.zib.de). All statistics were calculated using R (version 3.6.1, Team, 2011). The volumes of root-tissue and aerenchyma, as well as ratios between them were analyzed by means of a two-way ANOVA (response $\sim$ habitat * soil-depth) followed by Tukey HSD post-hoc tests, comparing Spartinahybrids from different habitats (tidal flat, pioneer marsh, tidal creek) at two soil depth intervals, i.e., top soil $(1-10 \mathrm{~cm})$ and deep soil $(10-20 \mathrm{~cm})$. Normality and homogeneity were confirmed by means of Shapiro-Wilk Normality and Levene's test. Differences in aerenchyma fragment volume were tested by means of a Kruskal-Wallis test followed by Mann-Whitney $U$ tests and Bonferroni-Holm adjustment. The linear regression analysis was 
conducted using the diagram generator of the R-package ggplot 2 by invoking function geom_smooth $($ method $=$ ' $1 \mathrm{~m}$ ', formula='y $\sim \mathrm{x}$ '). Ellipses for highlighting point-clouds were generated by function stat_ellipse(). The correlation coefficients were calculated using function cor.test(method = 'spearman').

\section{Results}

\subsection{Root and aerenchyma Volumes}

The root-system structure of $S . \times$ townsendii and $S$. anglica differed widely in different habitats (Fig. 3A). The root-tissue volume of $S . \times$ townsendii and $S$. anglica accounted for approximately $10 \%(\mathrm{v} / \mathrm{v})$ of the top soil volume (overall median: $9.1 \%(\mathrm{v} / \mathrm{v})$, interquartile range: $7.8-10.6 \%(\mathrm{v} / \mathrm{v})$; Fig. $3 \mathrm{~B})$. The root-aerenchyma volume in the top soil ranged from $0.4 \%$ (v/v; median; Fig. 3C) in $S . \times$ townsendii from the tidal flat to $2.2 \%$ (v/v; median) in S. anglica from the tidal creek. Deep rooting $(>10 \mathrm{~cm})$ was common in $S . \times$ townsendii and S. anglica in the pioneer zone, where the belowground root-tissue and root-aerenchyma volumes were very similar in the top and deep soil (deep soil, root-tissue median: 10.1 and $9.1 \%(\mathrm{v} / \mathrm{v})$, respectively). In contrast, deep root-tissue volume was limited in $S . \times$ townsendii from the tidal flat and S. anglica from the tidal creek (deep soil median: 3.6 and $3.7 \%(\mathrm{v} / \mathrm{v})$ ).

In the top soil, $S . \times$ townsendii from the tidal flat had a slightly lower proportion of roots with aerenchyma (91\% (v/v), median) than Spartina $\times$ townsendii (pioneer marsh), Spartina anglica (pioneer marsh), and Spartina anglica (tidal creek), where the proportion of roots with associated aerenchyma was more than $96 \%$ (v/v) (Fig. 3D). This difference was significant in the deep soil $(P<0.05)$ where Spartina $\times$ townsendii (tidal flat) had an even lower proportion of roots with associated aerenchyma (62\% (v/v), median), whereas the 
Spartina $\times$ townsendii (pioneer marsh), Spartina anglica (pioneer marsh), and Spartina anglica (tidal creek) remained at the same level compared to the top soil.

Figure3.pdf; See also affiliated PDF-file version!

Fig. 3: Root-system structure of $S . \times$ townsendii (tidal flat, pioneer marsh) and S. anglica (pioneer marsh, tidal creek). Illustration: A) Elevational gradient profile of Spartina habitats (tidal flat, pioneer marsh, tidal creek) in relation to mean high tide and examples for root-system reconstructions (red-yellow: roots; blue: aerenchyma). B - E: Diagrams of the root-tissue and root-aerenchyma volumes as well the relations between them in the top soil and deep soil. The letter-codes (a, b, c, d) are based upon ANOVA analyses followed by Tukey HSD post-hoc tests $(d f=3, n: 4$ soil cores $)$ and indicate differences in B) root-tissue volume $(F=16.4, P<0.05), \mathrm{C})$ root-aerenchyma volume $(F=14.7, P<0.05), \mathrm{D})$ the proportion of root-tissue volume associated with aerenchyma $(F=28.1, P<0.05)$, and $\mathrm{E})$ the proportion of aerenchyma volume per root-volume $(F=18.4, P<0.05)$. In the boxplots, the median is displayed as black horizontal line, the mean as orange diamond, and outliers as black dots outside the 1.5 of the interquartile range (box and whiskers). 
A
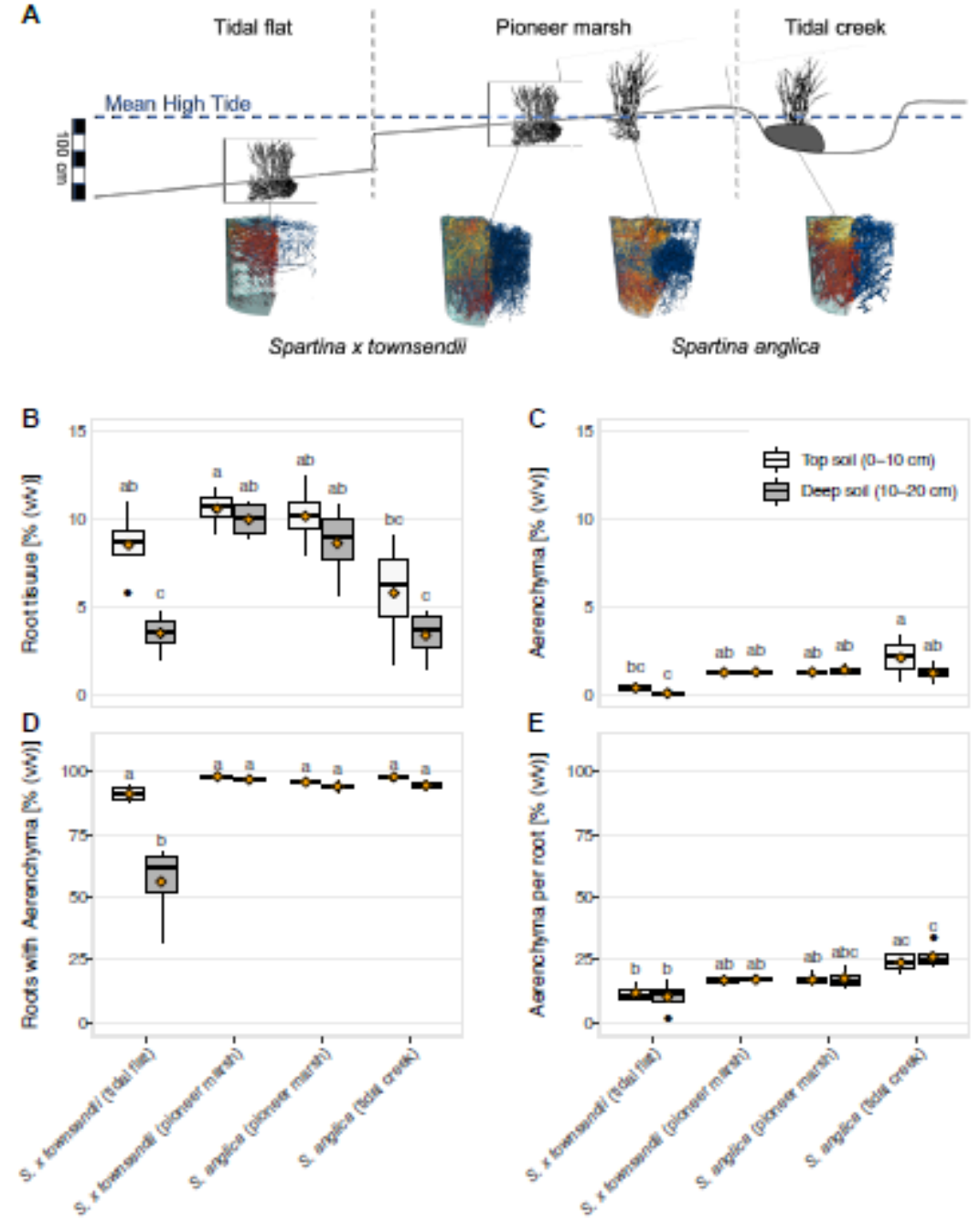

The root-system structure of Spartina anglica (tidal creek) was markedly different than Spartina from other habitats. In the tidal creek, S. anglica had the highest proportion of aerenchyma accounting for $27 \%$ (v/v) of the root volume (top soil; Fig. 3E). This was significantly different from $S . \times$ townsendii $(P<0.05)$ and slightly higher than in Spartina from pioneer marsh habitats (top soil; overall median: 16\% (v/v), interquartile range: 15 20).

Examples for root-system reconstructions of Spartina-taxa as well as root-tissue and rootaerenchyma volumes in relation to the considered soil depth are given in the Supplementary Material, Fig. S5A, C, D. Aerenchyma per root-volume was negatively correlated with X-ray 
density $(r=-0.56, P<0.001$; Supplementary Material, Fig. S6). $S . \times$ townsendii from the tidal flat showed a low proportion of aerenchyma per root-volume while mainly rooting in soil with comparatively higher X-ray density (sand fraction). Other Spartina (pioneer marsh, tidal creek) have been growing in soils with comparatively lower X-ray density (particulates fraction) and showed higher aerenchyma per root-volumes than $S . \times$ townsendii from the tidal flat.

For hexaploid $S . \times$ townsendii in the top soil, the root-tissue volume, root-aerenchyma volume, proportion of roots with aerenchyma, and aerenchyma per root-volume were only slightly lower in the tidal flat than in the pioneer marsh. In contrast, in the deep soil, the roottissue and aerenchyma volume of $S . \times$ townsendii stayed stable in the pioneer marsh, but the root-tissue volume decreased below $5 \%(\mathrm{v} / \mathrm{v})$ and aerenchyma volume dropped close to $0 \%$ $(\mathrm{v} / \mathrm{v})$ in the tidal flat. This was also reflected in the about $35 \%$ difference of the proportion of roots with aerenchyma in the deep soil between $S . \times$ townsendii from the tidal flat and the pioneer marsh.

For dodecaploid S. anglica, the root-tissue volume in the pioneer marsh accounted for $10 \%(\mathrm{v} / \mathrm{v})$ of the soil volume and was larger than in the tidal creek $(6 \%(\mathrm{v} / \mathrm{v}))$. This was only significant in the deep soil $(P<0.05)$, where the root-tissue volume of $S$. anglica in the tidal creek decreased below 5\% (v/v). Root-aerenchyma volumes and the percentage of roots with aerenchyma differed only slightly. Furthermore, S. anglica from the pioneer marsh showed a lower (not significant, $P \geq 0.05$ ) proportion of aerenchyma in roots, compared to plants from the tidal creek.

Hexaploid Spartina $\times$ townsendii (pioneer marsh) and dodecaploid Spartina anglica (pioneer marsh) differed only slightly (not significant, $P \geq 0.05$ ) in root-tissue volume, aerenchyma volume, percentage of roots with aerenchyma, and proportion of aerenchyma in 
roots. However, as described above, the differences in some of these parameters were higher between Spartina of the same ploidy level, i.e., hexaploid Spartina $\times$ townsendii (tidal flat) vs. Spartina $\times$ townsendii (pioneer marsh), and dodecaploid Spartina anglica (pioneer marsh) vs. Spartina anglica (tidal creek).

\subsection{Aerenchyma connectivity}

The root-aerenchyma fragment volumes differed significantly between Spartina ploidy levels $(P<0.001$; Fig. 4B) and Spartina-clones $(P<0.05$; Fig. 4C). However, the majority of rootaerenchyma fragments showed relatively small volumes below $1 \mathrm{~cm}^{3}$ ranging from 0.021 to $0.083 \mathrm{~cm}^{3}$ (median) regarding all Spartina-clones. Opposed to this, some aerenchyma fragments in the roots of S. anglica were extraordinarily extended (see outlier in Fig. 4C and Table 2) with a maximum fragment volume of $53.0 \mathrm{~cm}^{3}$ in the rhizome network of S. anglica in the tidal creek.

S. $\times$ townsendii in the tidal flat and in the pioneer marsh did not form extensively connected aerenchyma volumes. Opposed to this, the aerenchyma was highly connected in S. anglica in the tidal creek, where tube-like aerenchyma structures resulted in the largest root-aerenchyma fragment volumes and presumably a high connectivity into deeper soil layers (Fig. 4A). In S. anglica from the pioneer marsh, some aerenchyma fragment volumes were extraordinarily extended, showing a connected aerenchyma network. S. maritima also showed a connected aerenchyma network comparable to $S$. anglica from the pioneer marsh. However, these aerenchyma extents in S. maritima were approximately half in volume compared to S. anglica and mostly located in the upper half of the soil core (Fig. 4A; see also root system reconstruction in Supplementary Material, Fig. S7 - S12). S. alterniflora showed relatively small aerenchyma fragment-volumes and the maximum fragment-volume were approximately only a quarter of the largest fragment of S. maritima. 
Figure4.pdf; See also affiliated PDF-file version!

Fig. 4: Aerenchyma connectivity analysis of hexaploid S. alterniflora, S. maritima, S. $\times$ townsendii (tidal flat), and $S . \times$ townsendii (pioneer marsh) as well as dodecaploid S. anglica (pioneer marsh) and S. anglica (tidal creek). Illustrations: A) Reconstruction of root-aerenchyma fragments inside rhizomes (colors: separated root-aerenchyma fragments; white arrows: aerenchyma with extensive connectivity). Diagrams: B) Root-aerenchyma fragment volumes of Spartina of different ploidy levels (hexaploid, dodecaploid; y-axis restricted to $\leq 1 \mathrm{~cm}^{3}$; ***: Mann-Whitney-U test, $U=14.6, P<0.001, d f=1)$. C) Distribution of rootaerenchyma fragment volumes inside rhizomes of Spartina-clones (left diagram: zoomed view $\leq 1 \mathrm{~cm}^{3}$; right diagram: full view). The letter-codes (a, b, c, d) indicate differences between Spartina-clones (Kruskal-Wallis test followed by MannWhitney $U$ tests and Bonferroni-Holm adjustment, $H=150.0, P<0.05, d f=5$ ). In the boxplots, the median is displayed as horizontal line and outliers as dots outside the 1.5 of the interquartile range (box and whiskers); $n$ : root-aerenchyma fragments; all aerenchyma fragment volumes limited to $\geq 10 \mathrm{~mm}^{3}$. 
A
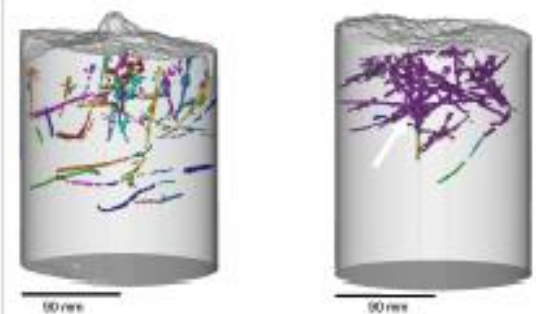

S. atemintora hexaploid

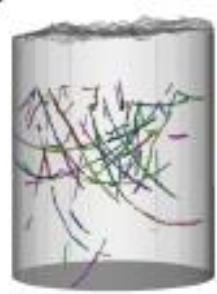

som

3. xtownsend:
ftodal flat? hexaid
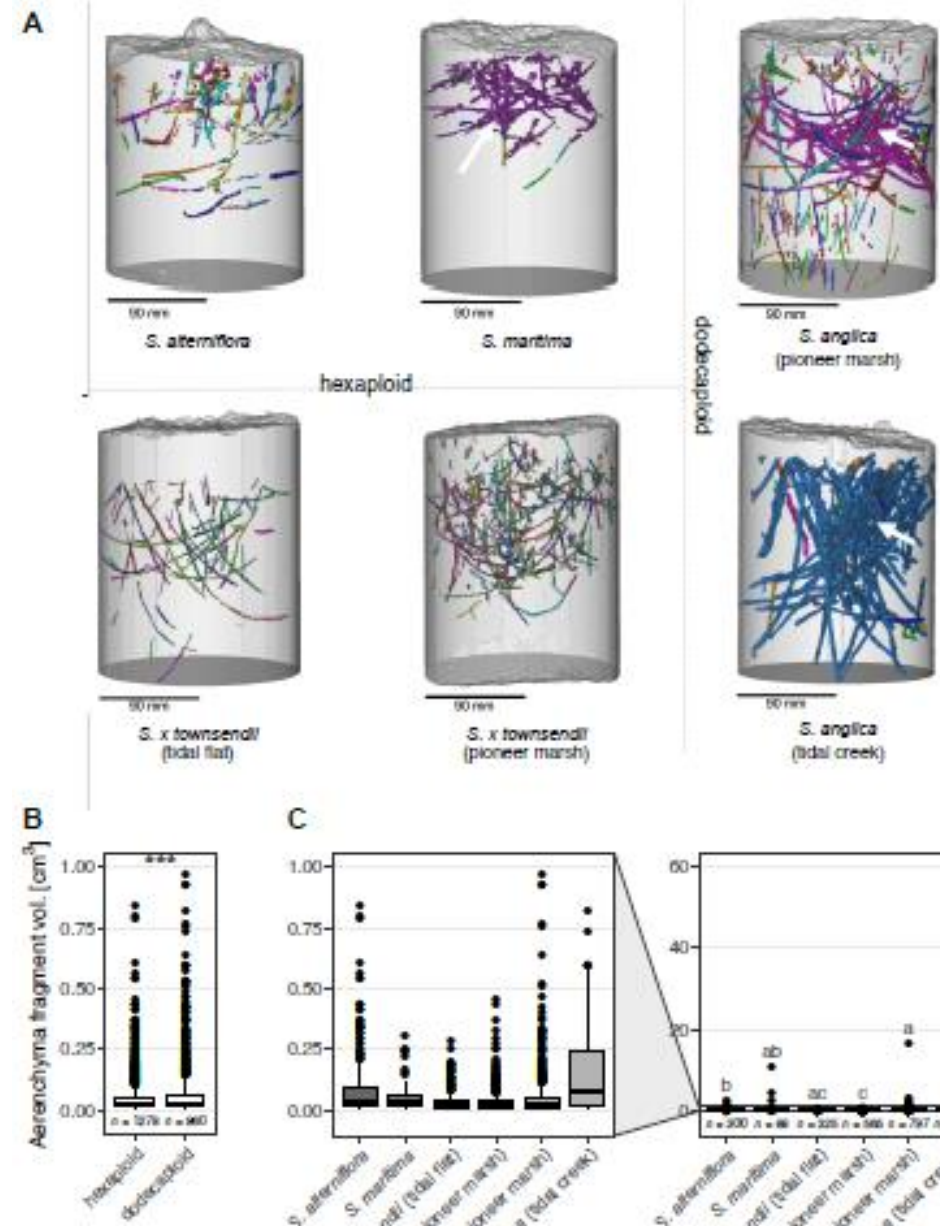

C

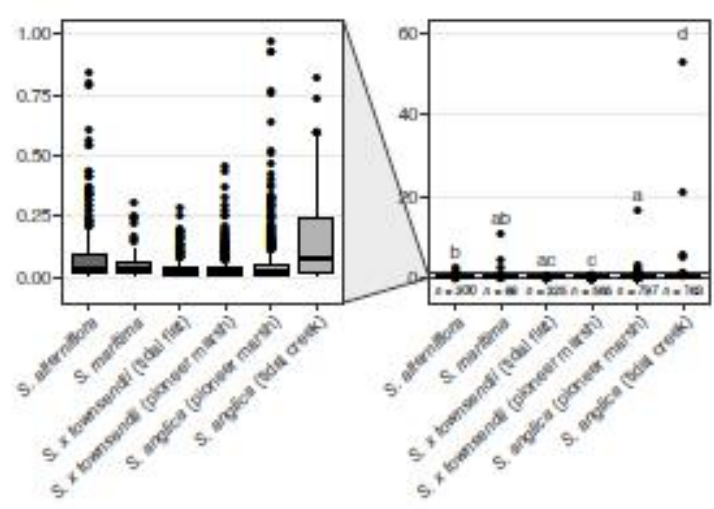

Table 2: Root-aerenchyma connectivity between ploidy levels (hexaploid and dodecaploid Spartina-clones) and of individual Spartina-clones considering soil depths deeper than $5 \mathrm{~cm}$ and regarding larger rhizomes with a minimum diameter of $1.4 \mathrm{~mm}$ and $70 \mathrm{~mm}$ in length. Inside rhizomes, the aerenchyma fragments with a minimum volume $\left(\geq 1 \mathrm{~cm}^{3}\right)$ indicate root-aerenchyma connectivity, particularly outliers with volumes above the 1.5 of the interquartile range. The letter-codes (A, B) indicate differences in aerenchyma fragment volumes (median) between ploidy levels (Mann-Whitney-U test, $U=14.6, P<0.001, d f=1$ ). The letter-codes (a, b, c, 
d) indicate differences in aerenchyma fragment volumes (median) between individual Spartina clones (Kruskal-Wallis test followed by Mann-Whitney $U$ tests and Bonferroni-Holm adjustment, $H=150.0, P<0.05, d f=5$ ).

Table2.docx; For table details see also affiliated PDF-file version!

\section{Discussion}

\subsection{Habitat control of Spartina root-system structure}

The root-system structures of Spartina-clones differed widely and showed clear responses to the conditions of their respective habitat. The presented results exhibit clear differences in deep soil root-tissue and root-aerenchyma volumes as well as the percentage of roots associated with aerenchyma between $S . \times$ townsendii from the tidal flat and the pioneer marsh. In deep soil, S. anglica from the tidal creek showed a higher proportion of aerenchyma than Spartina from the pioneer marsh. This supports for our first hypothesis that Spartina shows distinct root-system structures in response to habitat conditions differing in flooding regime, soil characteristics, and tidal hydrodynamics.

The belowground biomass structure of S. anglica in the tidal creek was different from Spartina-clones in other habitats. Compared to Spartina-clones from the pioneer marsh, S. anglica from the tidal creek showed comparable aerenchyma volumes, but the root-tissue volumes were smaller resulting in a higher proportion aerenchyma per root (Fig. 3B - D).

Most striking, the aerenchyma volume of $S . \times$ townsendii from the tidal flat was smallest in all soil depths. Even though it was the Spartina-clone on lowest elevation with the strongest flooding regimes. Specimens from this habitat should show the highest demand for root oxygenation under these waterlogged conditions, and therefore expected to form 
extensive aerenchyma (Evans, 2004; Purcell et al., 2019). This was however, not the case.

These observations show that the flooding conditions alone cannot predict the structure of the belowground biomass among different Spartina hybrids.

Redox potentials are known to play a key role in aerenchyma formation, showing extended aerenchyma formation under low redox conditions (Evans, 2004). In our study, aerenchyma responses were contrary to these expectations. S. anglica showed the highest aerenchyma formation in the tidal creek, which had the highest redox potential, and S. $\times$ townsendii showed lower aerenchyma development in the tidal flat than in the pioneer marsh, although the redox potentials were similar. Consequently, factors other than redox potential were important for shaping root-system structures in these marshes. It is noteworthy, that the redox potential in these marshes are higher than other more permanently water-logged marshes, and that the redox potential is highly dependent on flooding events (Table 1). The root-system development in $S . \times$ townsendii from the tidal flat may also have been affected by increased material density relative to other Spartina (pioneer marsh, tidal creek; Supplementary Material, Fig. S6). Opposed to $S . \times$ townsendii from the tidal flat, S. anglica from the tidal creek showed the highest aerenchyma response under comparatively high redox potentials. Consequently, factors other than redox potential have additionally been important in shaping root-system structures, such as nutrient supply by sea water.

Other factors such as biomechanical stress imposed by tidal hydrodynamic forces can also play a key role for the structural development of the biomass (Justin and Armstrong, 1987). Assuming that the biomechanical stress decreases with distance from the sea (tidal flat $>$ pioneer marsh > tidal creek; cf. Möller and Spencer, 2002), aerenchyma formation was negatively correlated to biomechanical stress in our study. This is in line with Justin and Armstrong (1987), who showed a decreased predisposition for aerenchyma formation in S. anglica under biomechanical stress. 


\subsection{Ploidy level versus habitat influence on Spartina root-system structure}

In the pioneer zone, monospecific stands of hexaploid $S . \times$ townsendii and dodecaploid S. anglica are located within a few meters of each other. This allows for a comparison of different hybrids with different ploidy-level under almost identical natural habitat conditions. None of the tested parameters, i.e., root-tissue volume, aerenchyma volume, proportion of roots with aerenchyma, and aerenchyma per root-volume, exhibited distinct differences between the two Spartina-taxa from the pioneer marsh (Fig. 3B - E). Therefore, we reject the $2^{\text {nd }}$ hypothesis that Spartina-taxa of different ploidy levels (hexa- and dodecaploid) show distinct root-system structures when growing in similar habitat conditions. Quite the opposite was the case, the root-system structures differed between Spartina-habitats rather than between Spartina-ploidy levels.

The only difference found between the hexaploid $S . \times$ townsendii and the dodecaploid S. anglica (Table 1) was in regard to stem-density. However, since none of the belowground biomass traits differed (Fig. 3B), our results indicate that root-biomass accumulation was driven by the condition of the habitat (cf. Mendelssohn and McKee, 1988; Koevoets et al., 2016; Mesa-Marín et al., 2018), rather than by polyploidization related effects, such as increased gene dosage (i.e., a doubling of the number of copies of a particular gene due to genome duplication and possibly accompanied by increases in the amount of gene products) or organ size (cf. Birchler et al., 2010; Doyle and Coate, 2019).

\subsection{Ploidy level controls aerenchyma connectivity}

The dodecaploid $S$. anglica-clones showed the largest root-aerenchyma fragment volumes compared to the hexaploid Spartina-clones. The highest aerenchyma connectivity was observed at $S$. anglica from the tidal creek bridging top soil and deep soil layers by highly aerenchymatous tube-like roots and rhizomes (Fig. 4A). Also in the pioneer marsh did 
dodecaploid S. anglica form a substantial aerenchyma network consisting of large fragments which was approximately five times larger than the largest aerenchyma network of the hexaploid samples (S. maritima). In the hexaploid parental S. alterniflora and hexaploid $\mathrm{F}_{1^{-}}$ hybrid $S . \times$ townsendii, extraordinarily large aerenchyma fragments were missing. The observation of the largest aerenchyma fragment volumes present in S. anglica was support for our $3^{\text {rd }}$ hypothesis that the dodecaploid S. anglica shows a higher aerenchyma connectivity than the hexaploid $\mathrm{F}_{1}$-hybrid and its parental Spartina-taxa. Interestingly, the hexaploid $\mathrm{F}_{1^{-}}$ hybrid $S . \times$ townsendii exhibited lower aerenchyma connectivity than its genome duplicated descendent $S$. anglica, which suggests that following this recent whole genome duplication, polyploidization per se, rather than hybridization affects this trait.

Aerenchyma fragment volumes differed generally between ploidy levels (Fig. 4B), which however, is rather difficult to consider in the assessment of aerenchyma connectivity because the majority of aerenchyma fragment volumes were relatively small (Table 2; overall median: $0.03 \mathrm{~cm}^{3}$ ). Our visual analysis of the reconstructed aerenchyma fragments revealed that the fragments were highly variable in length and diameter. The reconstructed aerenchyma fragments were often departing from the notion of tube-like aerenchyma formation that bridges root-tips with plant parts in the top soil. Rhizomes and roots with extended aerenchyma fragment volumes, i.e., orders of magnitude larger than the median, can be considered to be highly effective in aerenchyma connectivity, substantially lowering the resistance to continuous gas-flow (cf. Armstrong, 1980; Colmer, 2003). Maricle and Lee (2007) showed that the dodecaploid S. anglica has a significantly higher capacity for oxygen transport via root aerenchyma than the hexaploid S. alterniflora.

Previous findings by Maricle and Lee (2002) demonstrated by using light microscopy and cross-sectional area measurements that aerenchyma development in S. alterniflora and S. anglica was not different under drained but more extensive in S. alterniflora under flooded 
condition. In our study, the aerenchyma fragment volumes (median) of S. alterniflora were higher than the fragment volumes of $S$. anglica in the pioneer marsh (Table 2). In agreement with Maricle and Lee (2002) who directly measured oxygen transport capacity to be higher in S. anglica, we infer a higher capacity for gas-flow in S. anglica from our results. Our volumebased analysis of root-system structures allows to identify large aerenchyma structures in plants from undisturbed soil, and it also accounts for allometric growth effects (Weiner, 2004; Sugiyama, 2005): Cell-size and cell-volume immediately increase with polyploidization (e.g., Finigan et al., 2012; Roddy et al., 2019) and polyploid cells may therefore also differ in metabolic demands (Doyle and Coate, 2019). Due to allometric relationship, the volume-tosurface ratio of comparatively larger cells in polyploids is increased and may result in increased aerenchyma fragment volumes. Regarding lysigenous aerenchyma formation in plants on high ploidy level, such as dodecaploid S. anglica, large apoptotic cells in the root cortex would create relatively large aerenchyma volumes on a per cell base. In consequence, aerenchyma connectivity increases with ploidy level, if effects of polyploidization on cell size lead to merging aerenchyma fragments into large aerenchyma volumes.

The aerenchyma connectivity differed between the hexaploid $S . \times$ townsendii and the dodecaploid S. anglica as well as between S. anglica and the hexaploid parents. S. $\times$ townsendii was mimicking the phenotype of S. alterniflora: in both taxa, the aerenchyma formation was dominated by smaller fragments. In contrast, fragment volumes of $S$. maritima and S. anglica were larger with largest fragment volumes in S. anglica (Table 2). This may demonstrate maternal (S. alterniflora) dominance in aerenchyma connectivity in the $\mathrm{F}_{1}$-hybrid $(S . \times$ townsendii), shifting towards a transgressive phenotype (exceeding that of the largest parental phenotype, paternal S. maritima) after genome duplication (S. anglica). Other transgressive physiological traits were also observed in S. anglica, e.g., increased stress tolerance compared to the parents (Cavé-Radet et al., 2018). Effects of hybridization and 
whole genome duplication on the transcriptome of $S . \times$ townsendii and S. anglica were reported in previous investigations in this system (Chelaifa et al., 2010; Cavé-Radet et al., 2020), however, the way genetics is involved in the aerenchyma development in newly formed hybrids and allopolyploids is still an open question.

\subsection{Considerations for the ecosystem}

In Spartina dominated pioneer marshes, the root-tissue and aerenchyma combined accounted for a marked proportion of the top soil volume of $12 \%(\mathrm{v} / \mathrm{v})($ Fig. 3B - C). Accordingly, root-systems in salt marshes can have approximately twice the volume as the root-systems in terrestrial grasslands, for which Kuka et al. (2013) reported up to 7.1\% (v/v). Hence the belowground roots-system contributes to stabilization of the soil and prevention of erosion (cf. Van Eerdt, 1985; Ford et al., 2016; Hudek et al., 2017a). Furthermore, belowground biomass production contributes a substantial supply of organic carbon below the soil surface (Hudek et al., 2017b), which may support carbon sequestration in salt marshes and geomorphological resistance of salt marshes against sea level rise (Granse et al., 2020).

Our study showed that $S$. anglica had a well-developed aerenchyma-system consisting of larger fragments. This demonstrates that this dodecaploid S. anglica, in contrast to S. $\times$ townsendii and S. alterniflora, developed biomass structures that were particularly welladapted for belowground transport of oxygen. These findings support previous studies by Maricle and Lee (2007), showing that S. anglica has an outstanding gas transport capacity in comparison to other common wetland species. This trait provides S. anglica with the ability to modify its immediate belowground environment, removing phytotoxins and improving nutrient uptake. It predisposes the dodecaploid S. anglica for establishing in waterlogged anoxic soils outside the range of its hexaploid progenitors as a consequence of polyploidization (cf. Thompson, 1991; te Beest et al., 2012). The outstanding gas transport 
capacity of S. anglica may therefore be an important factor in its successful invasion of tidal wetlands around the world, from Australia to North America in a little more than a century.

\section{Conclusions}

Medical-CT-scanning followed by skeleton analysis was used for the 3D reconstruction of the roots-system architecture from different Spartina taxa and habitats. This approach enabled a quantitative measurement of the spatial distribution of roots and aerenchyma in undisturbed salt marsh soils, giving insights into aerenchyma formation and connectivity which cannot be obtained by other methods.

Soils in Spartina-dominated habitats are highly connected to the atmosphere via rootaerenchyma. The presence of root-aerenchyma of Spartina can exert strong impacts on the biogeochemistry of marsh soils. Our results stress the important role of Spartina as a key taxon for ecosystem functioning in salt marshes. We demonstrate that about $90 \%(\mathrm{v} / \mathrm{v})$ of the roots of Spartina have well developed aerenchyma and consequently more than $1 \%(\mathrm{v} / \mathrm{v})$ of the top soil volume in pioneer marshes consists of aerenchyma inside roots and rhizomes. This points to a high potential for plant-mediated oxygenation of anoxic soils.

The hexaploid $S . \times$ townsendii and the dodecaploid $S$. anglica showed similar aerenchyma when growing in the pioneer marsh. S. anglica from a tidal creek habitat showed smaller root biomass with more aerenchyma, while aerenchyma was lowest in $S . \times$ townsendii in the tidal flat. These results demonstrate that physicochemical habitat conditions control both root morphology and aerenchyma formation in the hexaploid S. $\times$ townsendii and the dodecaploid S. anglica. Flooding regime and soil redox conditions are likely to be main drivers of the observed habitat effects. Further studies are needed to specifically analyze the role of driving factors like biomechanical stress imposed by tidal forces in root and aerenchyma formation. Overall, environmental conditions seem to exert a stronger impact on the root-system 
structure of Spartina than ploidy level. However, a higher connectivity of root-aerenchyma was found in the dodecaploid S. anglica than in the hexaploids $S . \times$ townsendii, S. alterniflora and S. maritima. This may explain why earlier studies demonstrated a markedly higher oxygen transport capacity in S. anglica compared to other Spartina-taxa with lower ploidy levels.

\section{Acknowledgements}

We thank Armel Salmon (UMR CNRS 6553 Laboratory Ecobio, University of Rennes, France), for help in Spartina sampling. We thank Sigrid Suchrow for her indispensable advice and help during fieldwork, as well as Marion Klötzl, Maren Winnacker, and Paul Wendt for taking care of the plants. We further thank the authorities from the Nationalpark SchleswigHolsteinisches Wattenmeer for providing tidal data and the authorization of our fieldwork, the Wasserstraßen- und Schifffahrtsamt Tönning, Landesbetrieb für Küstenschutz, Nationalpark und Meeresschutz for providing tide gauge measurements, and the Landesamt für Vermessung und Geoinformation Schleswig-Holstein for providing the orthophotos of the study area. Klinikum Bremen-Mitte and Prof. Dr. Arne-Jörn Lemke and Christian Timann are thanked for providing their facilities and supporting the performed computed tomography measurements. All work was conducted in the framework of the project "Hybrids - Chances and Challenges of New Genetic Combinations", Universität Hamburg. We also thank the anonymous reviewers for their constructive and helpful suggestions.

\section{Author contributions}

Dirk Granse: Conceptualization, Methodology, Data curation, Writing (original draft preparation), Visualization, and Investigation. Jürgen Titschack: Validation, Methodology, and Writing (reviewing and editing). Kai Jensen, Ketil Koop-Jakobsen: Supervision, Writing (reviewing and editing). Malika Ainouche: Writing (reviewing and editing).

\section{Declarations of interest}

Declarations of interest: none 


\section{Research data}

The research data is published at PANGAEA - Database (Data Publisher for Earth \& Environmental Science, Ecology; https: / / doi .org/10.1594/PANGAEA.931784).

\section{References}

Ainouche, M. L., P. M. Fortune, A. Salmon, C. Parisod, M.-A. Grandbastien, K. Fukunaga, M. Ricou, and M.-T. Misset (2009). Hybridization, polyploidy and invasion: lessons from Spartina (Poaceae). In: Biological Invasions 11.5, 1159. doi: 10.1007/s10530-008-9383-2.

Ainouche, M., H. Chelaifa, J. Ferreira, S. Bellot, A. Ainouche, and A. Salmon (2012). Polyploid Evolution in Spartina: Dealing with Highly Redundant Hybrid Genomes. In: Polyploidy and Genome Evolution (Soltis, P. S. and D. E. Soltis, ed.). Berlin, Heidelberg: Springer Berlin Heidelberg. Chap. 12, 225—243. doi: 10.1007/978-3-642-31442-1_12.

An, S. Q., B. H. Gu, C. F. Zhou, Z. S. Wang, Z. F. Deng, Y. B. Zhi, H. L. Li, L. Chen, D. H. Yu, and Y. H. Liu (2007). Spartina invasion in China: implications for invasive species management and future research. In: Weed Research 47.3, 183-191. doi:

doi:10.1111/j.1365-3180.2007.00559.x.

Armstrong, J. and W. Armstrong (2009). Record rates of pressurized gas-flow in the great horsetail, Equisetum telmateia. Were Carboniferous Calamites similarly aerated? In: New Phytologist 184.1, 202-215. doi: 10.1111/j.1469-8137.2009.02907.x.

Armstrong, J., W. Armstrong, and P. M. Beckett (1992). Phragmites australis: Venturi- and humidity-induced pressure flows enhance rhizome aeration and rhizosphere oxidation. In: New Phytologist 120.2, 197-207. doi: 10.1111/j.1469-8137.1992.tb05655.x.

Armstrong, W. (1972). A Re-examination of the Functional Significance of Aerenchyma. In: Physiologia Plantarum 27.2, 173-177. doi: 10.1111/j.1399-3054.1972.tb03596.x.

- (1980). Aeration in Higher Plants. In: Advances in Botanical Research (Woolhouse, H. W. B. T., ed.). Vol. 7. Academic Press, 225-332. doi: https://doi.org/10.1016/S00652296(08)60089-0.

Balke, T., P. C. Klaassen, A. Garbutt, D. van der Wal, P. M. J. Herman, and T. J. Bouma (2012). Conditional outcome of ecosystem engineering: A case study on tussocks of the salt marsh pioneer Spartina anglica. In: Geomorphology 153-154, 232-238. doi:

https://doi.org/10.1016/j.geomorph.2012.03.002.

Belliard, J.-P., A. Silinski, D. Meire, G. Kolokythas, Y. Levy, A. Van Braeckel, T. Bouma, and S. Temmerman (2019). High-resolution bed level changes in relation to tidal and wave forcing on a narrow fringing macrotidal flat: Bridging intra-tidal, daily and seasonal sediment dynamics. In: Marine Geology 412. doi: 10.1016/j.margeo.2019.03.001.

Birchler, J. A., H. Yao, S. Chudalayandi, D. Vaiman, and R. A. Veitia (2010). Heterosis. In: The Plant Cell 22.7, 2105 LP -2112. doi: 10.1105/tpc.110.076133. 
Blum, L. and E. Davey (2013). Below the Salt Marsh Surface: Visualization of Plant Roots by Computer-Aided Tomography. In: Oceanography 26.3, 85-87. doi:

10.1001/jama.1906.02510280046005.

Bortolus, A., J. T. Carlton, and E. Schwindt (2015). Reimagining South American coasts: unveiling the hidden invasion history of an iconic ecological engineer. In: Diversity and Distributions 21.11, 1267-1283. doi: 10.1111/ddi.12377.

Bouma, T. J., K. L. Nielsen, and B. Koutstaal (2000). Sample preparation and scanning protocol for computerised analysis of root length and diameter. In: Plant and Soil 218.1, 185-196. doi: 10.1023/A:1014905104017.

Bradley, P. M. and J. T. Morris (1990). Influence of Oxygen and Sulfide Concentration on Nitrogen Uptake Kinetics in Spartina alterniflora. In: Ecology 71.1, 282-287. doi: $10.2307 / 1940267$.

Brix, H., B. K. Sorrell, and P. T. Orr (1992). Internal pressurization and convective gas flow in some emergent freshwater macrophytes. In: Limnology and Oceanography 37.7, 14201433. doi: 10.4319/lo.1992.37.7.1420.

Callaghan, D. P., T. J. Bouma, P. Klaassen, D. van der Wal, M. J. F. Stive, and P. M. J. Herman (2010). Hydrodynamic forcing on salt-marsh development: Distinguishing the relative importance of waves and tidal flows. In: Estuarine, Coastal and Shelf Science 89.1, 73-88. doi: https://doi.org/10.1016/j.ecss.2010.05.013.

Cavé-Radet, A., D. Giraud, O. Lima, A. El Amrani, M. Aïnouche, and A. Salmon (2020). Evolution of small RNA expression following hybridization and allopolyploidization: insights from Spartina species (Poaceae, Chloridoideae). In: Plant Molecular Biology 102.1, 55-72. doi: 10.1007/s11103-019-00931-w.

Cavé-Radet, A., A. Salmon, O. Lima, M. Ainouche, and A. EL Amrani (2018). Increased tolerance to organic xenobiotics following recent allopolyploidy in Spartina (Poaceae). In: Plant Science 280. doi: 10.1016/j.plantsci.2018.11.005.

Chelaifa, H., A. Monnier, and M. Ainouche (2010). Transcriptomic changes following recent natural hybridization and allopolyploidy in the salt marsh species Spartina $\times$ townsendii and Spartina anglica (Poaceae). In: New Phytologist 186.1, 161—174. doi: 10.1111/j.14698137.2010.03179.x.

Chirol, C., S. J. Carr, K. L. Spencer, and I. Moeller (2021). Pore, live root and necromass quantification in complex heterogeneous wetland soils using X-ray computed tomography. In: Geoderma 387, 114898. doi: https://doi.org/10.1016/j.geoderma.2020.114898.

Cnudde, V. and M. N. Boone (2013). High-resolution X-ray computed tomography in geosciences: A review of the current technology and applications. In: Earth-Science Reviews 123, 1-17. doi: https://doi.org/10.1016/j.earscirev.2013.04.003.

Colmer, T. D. (2003). Aerenchyma and an inducible barrier to radial oxygen loss facilitate root aeration in upland, paddy and deep-water rice (Oryza sativa L.) eng. In: Annals of botany 91 Spec No.2, 301-309. doi: 10.1093/aob/mcf114. 
Davey, E., C. Wigand, R. Johnson, K. Sundberg, J. Morris, and C. T. Roman (2011). Use of computed tomography imaging for quantifying coarse roots, rhizomes, peat, and particle densities in marsh soils. In: Ecological Applications 21.6, 2156-2171. doi: 10.1890/102037.1.

De Lange, M. and M. Paulissen (2016). Efficiency of three halophyte species in removing nutrients from saline water: a pilot study. In: Wetlands Ecology and Management 24. doi: $10.1007 / \mathrm{s} 11273-016-9489-8$.

Doyle, J. J. and J. E. Coate (2019). Polyploidy, the Nucleotype, and Novelty: The Impact of Genome Doubling on the Biology of the Cell. In: International Journal of Plant Sciences 180.1, 1-52. doi: 10.1086/700636.

Edmaier, K., P. Burlando, and P. Perona (2011). Mechanisms of vegetation uprooting by flow in alluvial non-cohesive sediment. In: Hydrology and Earth System Sciences 15. doi: 10.5194/hess-15-1615-2011.

Esselink, P., J. Petersen, S. Arens, B. J.P., J. Bunje, K. Dijkema, N. Hecker, U. Hellwig, A.V. Jensen, A. Kers, P. Körber, E. Lammerts, M. Stock, R. Veeneklaas, M. Vreeken, and M. Wolters (2009). Salt Marshes. Thematic Report No. 8. In: Wadden Sea Ecosystem No. 25 Quality Status Report 2009 Thematic Report No. 8 46.4, 27-30.

Evans, D. E. (2004). Aerenchyma formation. In: New Phytologist 161.1, 35—49. doi: 10.1046/j.1469-8137.2003.00907.x.

Finigan, P., M. Tanurdzic, and R. A. Martienssen (2012). Origins of Novel Phenotypic Variation in Polyploids BT - Polyploidy and Genome Evolution. In: (Soltis, P. S. and D. E. Soltis, ed.). Springer Berlin Heidelberg, 57-76. doi: 10.1007/978-3-642-31442-1_4.

Ford, H., A. Garbutt, C. Ladd, J. Malarkey, and M. W. Skov (2016). Soil stabilization linked to plant diversity and environmental context in coastal wetlands. In: Journal of Vegetation Science 27.2, 259-268. doi: 10.1111/jvs.12367.

Fox, D. T., D. E. Soltis, P. S. Soltis, T.-L. Ashman, and Y. Van de Peer (2020). Polyploidy: A Biological Force From Cells to Ecosystems. In: Trends in Cell Biology 30.9, 688 - 694. doi: https://doi.org/10.1016/j.tcb.2020.06.006.

French, J. R. and D. R. Stoddart (1992). Hydrodynamics of salt marsh creek systems: Implications for marsh morphological development and material exchange. In: Earth Surface Processes and Landforms 17.3, 235-252. doi: https://doi.org/10.1002/esp.3290170304.

Gao, W., S. Schlüter, S. R. G. A. Blaser, J. Shen, and D. Vetterlein (2019). A shape-based method for automatic and rapid segmentation of roots in soil from X-ray computed tomography images: Rootine. In: Plant and Soil 441.1, 643 - 655. doi: 10.1007/s11104-01904053-6.

Granse, D., S. Suchrow, and K. Jensen (2020). Long-term invasion dynamics of Spartina increase vegetation diversity and geomorphological resistance of salt marshes against sea level rise. In: Biological Invasions. doi: 10.1007/s 10530-020-02408-0. 
Gray, A. J., D. F. Marshall, and A. F. Raybould (1991). A Century of Evolution in Spartina anglica. In: Advances in Ecological Research 21, 1-62. doi:

http://dx.doi.org/10.1016/S0065-2504(08)60096-3.

Hacker, S. D., D. Heimer, C. E. Hellquist, T. G. Reeder, B. Reeves, T. J. Riordan, and M. N. Dethier (2001). A Marine Plant (Spartina anglica) Invades Widely Varying Habitats:

Potential Mechanisms of Invasion and Control. In: Biological Invasions 3.2, 211-217. doi: 10.1023/A:1014555516373.

Hamersley, M. and B. Howes (2005). Coupled nitrification-denitrification measured in situ in a Spartina alterniflora marsh with a (NH4+)-N-15 tracer. In: Marine Ecology Progress Series 299. doi: 10.3354/meps299123.

Hanson, A., R. Johnson, C. Wigand, A. Oczkowski, E. Davey, and E. Markham (2016). Responses of Spartina alterniflora to Multiple Stressors: Changing Precipitation Patterns, Accelerated Sea Level Rise, and Nutrient Enrichment. In: Estuaries and Coasts 39.5, 13761385. doi: 10.1007/s12237-016-0090-4.

Hounsfield, G. N. (1979). COMPUTED MEDICAL IMAGING. In: Nobel Lecture 8, 1-19.

Hudek, C., S. Stanchi, M. D'amico, and M. Freppaz (2017a). Quantifying the contribution of the root system of alpine vegetation in the soil aggregate stability of moraine. In: Journal of Soil and Water Conservation 5. doi: 10.1016/j.iswcr.2017.02.001.

Hudek, C., C. Sturrock, B. S. Atkinson, S. Stanchi, and M. Freppaz (2017b). Root morphology and biomechanical characteristics of high altitude alpine plant species and their potential application in soil stabilization. In: Ecological Engineering 109. doi: 10.1016/j.ecoleng.2017.05.048.

Hulzen, J. B. van, J. van Soelen, and T. J. Bouma (2007). Morphological variation and habitat modification are strongly correlated for the autogenic ecosystem engineer Spartina anglica (common cordgrass). In: Estuaries and Coasts 30.1, 3-11. doi: 10.1007/BF02782962.

Jackson, M. B. and W. Armstrong (1999). Formation of Aerenchyma and the Processes of Plant Ventilation in Relation to Soil Flooding and Submergence. In: Plant Biology 1.3, 274287. doi: 10.1111/j.1438-8677.1999.tb00253.x.

Justin, A. S. H. F. W. and W. Armstrong (1987). The Anatomical Characteristics of Roots and Plant Response to Soil Flooding. In: New Phytologist 106.3, 465-495.

Koevoets, I. T., J. H. Venema, J. T. M. Elzenga, and C. Testerink (2016). Roots Withstanding their Environment: Exploiting Root System Architecture Responses to Abiotic Stress to Improve Crop Tolerance. In: 7, 1335.

König, D. (1948). Spartina townsendii an der Westküste von Schleswig-Holstein. In: Planta 36.1, 34-70. doi: 10.1007/BF01917217.

Koop-Jakobsen, K., J. Fischer, and F. Wenzhöfer (2017). Survey of sediment oxygenation in rhizospheres of the saltmarsh grass - Spartina anglica. In: Science of The Total Environment 589, 191—199. doi: http://dx.doi.org/10.1016/j.scitotenv.2017.02.147. 
Koop-Jakobsen, K. and A. E. Giblin (2010). The effect of increased nitrate loading on nitrate reduction via denitrification and DNRA in salt marsh sediments. In: Limnology and Oceanography 55.2, 789—802. doi: 10.4319/lo.2010.55.2.0789.

Koop-Jakobsen, K. and M. S. Gutbrod (2019). Shallow Salt Marsh Tidal Ponds-An Environment With Extreme Oxygen Dynamics. In: 7, 137.

Koop-Jakobsen, K., P. Mueller, R. J. Meier, G. Liebsch, and K. Jensen (2018). PlantSediment Interactions in Salt Marshes - An Optode Imaging Study of $\mathrm{O}_{2}, \mathrm{pH}$, and $\mathrm{CO}_{2}$ Gradients in the Rhizosphere. In: 9, 541.

Koop-Jakobsen, K. and F. Wenzhöfer (2015). The Dynamics of Plant-Mediated Sediment Oxygenation in Spartina anglica Rhizospheres - a Planar Optode Study. In: Estuaries and Coasts. doi: 10.1007/s12237-014-9861-y.

Kuka, K., B. Illerhaus, C. A. Fox, and M. Joschko (2013). X-ray Computed Microtomography for the Study of the Soil-Root Relationship in Grassland Soils. In: Vadose Zone Journal 12.4, vzj2013.01.0014. doi: 10.2136/vzj2013.01.0014.

Lai, W.-L., Y. Zhang, and Z.-H. Chen (2012). Radial oxygen loss, photosynthesis, and nutrient removal of 35 wetland plants. In: Ecological Engineering 39, 24-30. doi: https://doi.org/10.1016/j.ecoleng.2011.11.010.

Lee, R. W. (2003). Physiological adaptations of the invasive cordgrass Spartina anglica to reducing sediments: rhizome metabolic gas fluxes and enhanced $\mathrm{O}_{2}$ and $\mathrm{H}_{2} \mathrm{~S}$ transport. In: Marine Biology 143.1, 9-15. doi: 10.1007/s00227-003-1054-3.

Lee, R. W., D. W. Kraus, and J. E. Doeller (1999). Oxidation of sulfide by Spartina alterniflora roots. In: Limnology and Oceanography 44.4, 1155-1159. doi: 10.4319/lo.1999.44.4.1155.

Maherali, H., A. E. Walden, and B. C. Husband (2009). Genome duplication and the evolution of physiological responses to water stress. In: New Phytologist 184.3, 721-731. doi: 10.1111/j.1469-8137.2009.02997.x.

Mansfeldt, T. (2003). In situ long-term redox potential measurements in a dyked marsh soil. In: Journal of Plant Nutrition and Soil Science 166.2, 210-219. doi:

10.1002/jpln.200390031.

Marchant, C. J. (1967). Evolution in Spartina (Gramineae): I. The history and morphology of the genus in Britain. In: Journal of the Linnean Society of London, Botany 60.381, 1-24. doi: 10.1111/j.1095-8339.1967.tb00076.x.

- (1968). Evolution in Spartina (Gramineae): II. Chromosomes, basic relationships and the problem of S. x townsendii agg. In: Journal of the Linnean Society of London, Botany 60.383, 381-409. doi: 10.1111/j.1095-8339.1968.tb00096.x.

Maricle, B. R., J. J. Crosier, B. C. Bussiere, and R. W. Lee (2006). Respiratory enzyme activities correlate with anoxia tolerance in salt marsh grasses. In: Journal of Experimental Marine Biology and Ecology 337.1, 30-37. doi:

https://doi.org/10.1016/j.jembe.2006.05.019. 
Maricle, B. R. and R. W. Lee (2002). Aerenchyma development and oxygen transport in the estuarine cordgrasses Spartina alterniflora and S. anglica. In: Aquatic Botany 74.2, 109120. doi: http://dx.doi.org/10.1016/S0304-3770(02)00051-7.

- (2007). Root respiration and oxygen flux in salt marsh grasses from different elevational zones. In: Marine Biology 151.2, 413 - 423. doi: 10.1007/s00227-006-0493-z.

Meeus, S., K. Šemberová, N. De Storme, D. Geelen, and M. Vallejo-Marín (2020). Effect of Whole-Genome Duplication on the Evolutionary Rescue of Sterile Hybrid Monkeyflowers. In: Plant Communications, 100093. doi: 10.1016/j.xplc.2020.100093.

Mendelssohn, I. A. and K. L. McKee (1988). Spartina alterniflora Die-Back in Louisiana: Time-Course Investigation of Soil Waterlogging Effects. In: Journal of Ecology 76.2, 509521. doi: $10.2307 / 2260609$.

Mendelssohn, I., K. McKee, and W. Patrick (1981). Oxygen Deficiency in Spartina alterniflora Roots: Metabolic Adaptation to Anoxia. In: Science (New York, N.Y.) 214, 439-441. doi: 10.1126/science.214.4519.439.

Mesa-Marín, J., N. F. Del-Saz, I. D. Rodríguez-Llorente, S. Redondo-Gómez, E. Pajuelo, M. Ribas-Carbó, and E. Mateos-Naranjo (2018). PGPR Reduce Root Respiration and Oxidative Stress Enhancing Spartina maritima Root Growth and Heavy Metal Rhizoaccumulation. In: Frontiers Plant Science 9.1500.

Möller, I. and T. Spencer (2002). Wave dissipation over macro-tidal saltmarshes: Effects of marsh edge typology and vegetation change. In: Journal of Coastal Research 36.1, 506 — 521.

Mueller, P., D. Granse, S. Nolte, M. Weingartner, S. Hoth, and K. Jensen (2020).

Unrecognized controls on microbial functioning in Blue Carbon ecosystems: The role of mineral enzyme stabilization and allochthonous substrate supply. In: Ecology and Evolution 10.2, 998-1011. doi: 10.1002/ece3.5962.

Müntzing, A. (1936). The Evolutionary Significance of Autopolyploidy. Vol. 21, 363-378. doi: 10.1111/j.1601-5223.1936.tb03204.x.

Pezeshki, S. R. (2001). Wetland plant responses to soil flooding. In: Environmental and Experimental Botany 46.3, 299-312. doi: https://doi.org/10.1016/S0098-8472(01)00107-1.

Proença, B., T. Nez, A. Poli, A. Ciutat, L. Devaux, A. Sottolichio, X. de Montaudouin, and R. Michalet (2019). Intraspecific facilitation explains the spread of the invasive engineer Spartina anglica in Atlantic salt marshes. In: Journal of Vegetation Science 30.2, 212-223. doi: $10.1111 /$ jvs.12720.

Purcell, A. S. T., W. G. Lee, A. J. Tanentzap, and D. C. Laughlin (2019). Fine Root Traits Are Correlated with Flooding Duration while Aboveground Traits Are Related to Grazing in an Ephemeral Wetland. In: Wetlands 39.2, 291-302. doi: 10.1007/s13157-018-1084-8.

Ramsey, J. and D. W. Schemske (2002). Neopolyploidy in Flowering Plants. In: Annual Review of Ecology and Systematics 33.1, 589-639. doi:

10.1146/annurev.ecolsys.33.010802.150437. 
Ranwell, D. S. (1967). World Resources of Spartina townsendii (sensu lato) and Economic Use of Spartina Marshland. In: Journal of Applied Ecology 4.1, 239-256. doi:

$10.2307 / 2401421$

Redelstein, R., T. Dinter, D. Hertel, and C. Leuschner (2018). Effects of Inundation, Nutrient Availability and Plant Species Diversity on Fine Root Mass and Morphology Across a Saltmarsh Flooding Gradient. In: 9, 98.

Roddy, A. B., G. Théroux-Rancourt, T. Abbo, J. W. Benedetti, C. R. Brodersen, M. Castro, S Castro, A. B. Gilbride, B. Jensen, G.-F. Jiang, J. A. Perkins, S. D. Perkins, J. Loureiro, Z. Syed, R. A. Thompson, S. E. Kuebbing, and K. A. Simonin (2019). The scaling of genome size and cell size limits maximum rates of photosynthesis with implications for ecological strategies. In: bioRxiv, 619585. doi: 10.1101/619585.

Shang, L., L.-F. Li, Z.-P. Song, Y. Wang, J. Yang, C.-C. Wang, S.-Y. Qiu, J.-X. Huang, M. Nie, L. M. Wolfe, and B. Li (2019). High Genetic Diversity With Weak Phylogeographic Structure of the Invasive Spartina alterniflora (Poaceae) in China. In: Frontiers in Plant Science 10, 1467.

Stalling, D., M. Westerhoff, and H.-C. Hege (2005). Amira - a Highly Interactive System for Visual Data Analysis. In: The visualization handbook (Hansen, C. and C. Johnson, ed.). Burlington.: Butterworth-Heinemann. Chap. 1, 1-18.

Stebbins, G. L. (1971). Chromosomal evolution in higher plants [by] G. Ledyard Stebbins (Barrington, E. J. W. and A. J. Willis, ed.). Contempora. London: Edward Arnold, viii, 216 p.

Strong, D. R. and D. R. Ayres (2013). Ecological and Evolutionary Misadventures of Spartina. In: Annual Reviews 44, 389-410. doi: 10.1146/annurev-ecolsys-110512-135803.

Sugiyama, S.-I. (2005). Polyploidy and Cellular Mechanisms Changing Leaf Size: Comparison of Diploid and Autotetraploid Populations in Two Species of Lolium. In: Annals of Botany 96.5, 931—938. doi: 10.1093/aob/mci245.

te Beest, M., J. J. Le Roux, D. M. Richardson, A. K. Brysting, J. Suda, M. Kubešová, and P. Pyšek (2012). The more the better? The role of polyploidy in facilitating plant invasions. In: Annals of Botany 109.1, 19—45.

Teal, J. M. and J. W. Kanwisher (1966). Gas Transport in the Marsh Grass, Spartina alterniflora. In: Journal of Experimental Botany 17.51, 355-361.

Team, R. D. C. (2011). R: A Language and Environment for Statistical Computing.

Thompson, J. D., T. McNeilly, and A. J. Gray (1991). Population Variation in Spartina anglica C. E. Hubbard. III. Response to Substrate Variation in a Glasshouse Experiment. In: The New Phytologist 117.1, 141-152.

Thompson, J. D. (1991). The Biology of an Invasive Plant: What makes Spartina anglica so successful? In: BioScience 41.6, 393-401. doi: 10.2307/1311746.

Valiela, I., J. M. Teal, and W. G. Deuser (1978). The Nature of Growth Forms in the Salt Marsh Grass Spartina alterniflora. In: The American Naturalist 112.985, 461-470. 
Van Eerdt, M. M. (1985). Salt marsh cliff stability in the Oosterschelde. In: Earth Surface Processes and Landforms 10.2, 95-106. doi: 10.1002/esp.3290100203.

Visser, E. J. W., T. D. Colmer, C. W. P. M. Blom, and L. A. C. J. Voesenek (2000). Changes in growth, porosity, and radial oxygen loss from adventitious roots of selected mono- and dicotyledonous wetland species with contrasting types of aerenchyma. In: Plant, Cell \& Environment 23.11, 1237-1245. doi: 10.1046/j.1365-3040.2000.00628.x.

Weiner, J. (2004). Allocation, plasticity and allometry in plants. In: Perspectives in Plant Ecology, Evolution and Systematics 6.4, 207-215. doi: https://doi.org/10.1078/1433-831900083.

Widdows, J., N. D. Pope, and M. D. Brinsley (2008). Effect of Spartina anglica stems on near-bed hydrodynamics, sediment erodability and morphological changes on an intertidal mudflat. In: Marine Ecology Progress Series 362, 45-57.

Wigand, C., K. Sundberg, A. Hanson, E. Davey, R. Johnson, E. Watson, and J. Morris (2016). Varying inundation regimes differentially affect natural and sand-amended marsh sediments. In: PLoS ONE 11.10. doi: 10.1371/journal.pone.0164956.

Wong, J., F. Costantini, N. Merloni, L. Savelli, D. Geelen, and L. Airoldi (2018). The widespread and overlooked replacement of Spartina maritima by non-indigenous S. anglica and $S$. townsendii in north-western Adriatic saltmarshes. In: Biological Invasions. doi: 10.1007/s 10530-017-1654-3. 


\section{Declaration of interests}

$\bigotimes$ The authors declare that they have no known competing financial interests or personal relationships that could have appeared to influence the work reported in this paper.

$\square$ The authors declare the following financial interests/personal relationships which may be considered as potential competing interests: 


\section{Credit-Author-Statement}

Dirk Granse: Conceptualization, Methodology, Data curation, Writing (original draft preparation), Visualization, and Investigation. Jürgen Titschack: Validation, Methodology, and Writing (reviewing and editing). Kai Jensen, Ketil Koop-Jakobsen: Supervision, Writing (reviewing and editing). Malika Ainouche: Writing (reviewing and editing). 
Table 1:

\begin{tabular}{|l|r|r|r|r|}
\hline & \multicolumn{2}{|c|}{ S. $\times$ townsendii } & \multicolumn{2}{c|}{ S. anglica } \\
\hline & tidal flat & pioneer marsh & pioneer marsh & tidal creek \\
\hline $\begin{array}{l}\text { Elevation MHT } \\
{[\mathrm{cm}]}\end{array}$ & -86 & -6 & 7 & -5 \\
\hline $\begin{array}{l}\text { Soil bulk density } \\
{\left[\mathrm{g} \cdot 100 \mathrm{~cm}^{-3}\right]}\end{array}$ & 121 & 75 & 94 & 68 \\
\hline $\begin{array}{l}\text { Redox after } \\
\text { high-tide [mV] }\end{array}$ & 82 & -37 & -28 & 194 \\
\hline $\begin{array}{l}\text { Redox before } \\
\text { high-tide [mV] }\end{array}$ & 264 & 318 & 273 & 367 \\
\hline $\begin{array}{l}\text { Reducing depth } \\
{[\mathrm{cm}]}\end{array}$ & 0 & 9 & 0 & 14 \\
\hline $\begin{array}{l}\text { Stem density [m } \\
\left.{ }^{-}\right]\end{array}$ & 1329 & 2304 & 975 & 414 \\
\hline $\begin{array}{l}\text { Old stem density } \\
{\left[\mathrm{m}^{-2}\right]}\end{array}$ & 148 & 473 & 414 & 0 \\
\hline
\end{tabular}




\begin{tabular}{|c|c|c|c|c|c|c|c|c|}
\hline & $\begin{array}{r}\text { hexaplo } \\
\mathrm{id}\end{array}$ & $\begin{array}{r}\text { dodecaplo } \\
\mathrm{id}\end{array}$ & $\begin{array}{r}S . \\
\text { alterniflo } \\
\text { ra }\end{array}$ & $\begin{array}{r}S . \\
\text { mariti } \\
\text { ma }\end{array}$ & $\begin{array}{r}S . \times \\
\text { townsen } \\
\text { dii (tidal } \\
\text { flat) }\end{array}$ & $\begin{array}{r}S . \times \\
\text { townsen } \\
\text { dii } \\
\text { (pioneer } \\
\text { marsh) }\end{array}$ & $\begin{array}{r}S . \\
\text { anglic } \\
a \\
\text { (pione } \\
\text { er } \\
\text { marsh) }\end{array}$ & $\begin{array}{r}S . \\
\text { anglic } \\
a \\
\text { (tidal } \\
\text { creek) }\end{array}$ \\
\hline $\begin{array}{l}\text { Rhizom } \\
\mathrm{e} \\
\text { volume } \\
{\left[\mathrm{cm}^{3}\right]}\end{array}$ & 782 & 875 & 184 & 80 & 195 & 301 & 564 & 310 \\
\hline \multicolumn{9}{|c|}{ Aerenchyma fragment volume $\left[\mathrm{cm}^{3}\right]$} \\
\hline - total & 86 & 182 & 30 & 22 & 13 & 21 & 71 & 111 \\
\hline $\begin{array}{l}\text { - total } \\
\text { (outlier) }\end{array}$ & 52 & 153 & 17 & 20 & 5 & 8 & 49 & 90 \\
\hline $\begin{array}{l}- \\
\text { maximu } \\
\text { m }\end{array}$ & 10.7 & 53.0 & 2.2 & 10.7 & 0.3 & 0.5 & 16.5 & 53.0 \\
\hline - & $0.02^{\mathrm{B}}$ & $0.03^{\mathrm{A}}$ & $0.04^{\mathrm{b}}$ & $0.03^{\mathrm{ab}}$ & $0.02^{\mathrm{ac}}$ & $0.02^{\mathrm{c}}$ & $0.03^{\mathrm{a}}$ & $0.08^{\mathrm{d}}$ \\
\hline $\begin{array}{l}\text { - outlier } \\
(\%)\end{array}$ & $60 \%$ & $84 \%$ & $58 \%$ & $87 \%$ & $38 \%$ & $40 \%$ & $70 \%$ & $81 \%$ \\
\hline
\end{tabular}

Table 2: 
Graphical abstract

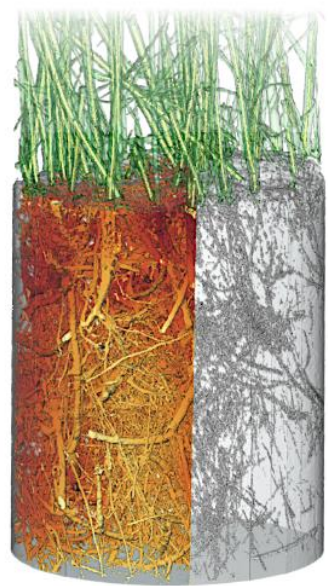

CT-scan reconstruction

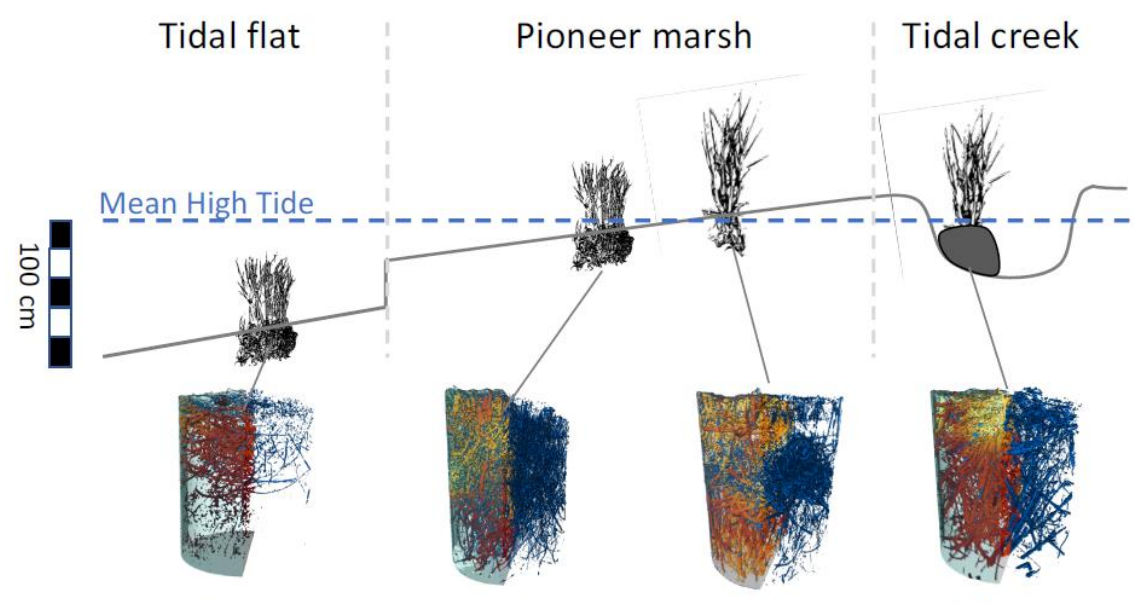

Spartina $x$ townsendii

Spartina anglica 
Highlights

- 3D root-system architecture of Spartina visualized by CT-scanning

- Root-system quantification of Spartina in native soils using skeleton analysis

- Spartina root-system structure formation is controlled by habitat conditions

- High capacity for aerenchyma development in both hexaploid and dodecaploid Spartina

- Genome duplicated Spartina anglica shows markedly higher oxygen transport

capacity 